\title{
Spawanie produkcyjne odlewu staliwnego żaroodpornego GX40NiCrNb35-45
}

\author{
Production welding of a heat-resistant cast steel \\ GX40NiCrNb35-45
}

\begin{abstract}
Streszczenie
W pracy przedstawiono przykładowe wyniki badań kwalifikowania technologii spawania produkcyjnego odlewu staliwnego żaroodpornego w gatunku GX40NiCrNb35-45 przy użyciu materiału dodatkowego w gatunku WZ 3545 Zr wg PN-EN ISO 14343. Badanie kwalifikowania technologii spawania wykonano zgodnie z PN-EN ISO 11970. Złącze próbne wykonano metodą 141 i następnie przeprowadzono badania nieniszczące oraz niszczące określające własności mechaniczne złącza. Wykonane badania pozwoliły spełnić wymagania zawarte w PN-EN ISO 11970 i były podstawą do wystawienia protokołu kwalifikowania technologii spawania.
\end{abstract}

Słowa kluczowe: kwalifikowanie technologii spawania; staliwo żaroodporne; spawanie TIG

\begin{abstract}
The paper presents the results of qualification of production welding procedures for heat-resistant cast steel in grade GX40NiCrNb35-45 with used filler material in grade WZ3545 Zr (PN-EN ISO 14343). Qualification of welding technology was made in accordance to PN-EN ISO 11970. Test welded joint was made using 141 method and non-destructive and destructive testing were performed in order to determine the mechanical properties of the welded joint. Completed tests met the requirements of PN-EN ISO 11970 and were the basis of the welding procedure qualification record.
\end{abstract}

Keywords: qualification of welding procedures; heat-resistant cast steel; TIG welding

\section{Wstęp}

Staliwa wysokostopowe żaroodporne austenityczne są szeroko stosowane na elementy instalacji w zakładach naftowych, petrochemicznych i chemicznych. Od żaroodpornych odlewów staliwnych stosowanych na ww. elementy instalacji wymaga się stabilności mikrostruktury, żarowytrzymałości, odporności na nawęglanie i utlenianie, przy zachowaniu dobrej spawalności [1]. Elementy instalacji podczas pracy narażone są na ekstremalnie wysokie temperatury ok. $800 \div 1100^{\circ} \mathrm{C}$. Takie warunki powodują degradację mikrostruktury różnymi mechanizmami. Począwszy od kruchości wywołanej pełzaniem, wysokotemperaturowego zmęczenia, kruchości wywołanej przez fazę sigma, nawęglenie, kruchości wodorowej, grafityzacji, erozji, korozji wysokotemperaturowej [2]. W czasie pracy w podwyższonej temperaturze, głównymi wydzieleniami jakie powstają są węgliki bogate w chrom typu $\mathrm{Cr}_{23} \mathrm{C}_{6}, \mathrm{M}_{6}(\mathrm{C}, \mathrm{N})$, węgliki bogate $\mathrm{w}$ niob typu $\mathrm{NbC}$, węgliko-azotki $\mathrm{Cr}_{2}(\mathrm{C}, \mathrm{N})[2]$.

W mikrostrukturze stopów GX zawierających Nb w stanie lanym oprócz osnowy austenitycznej występują węgliki niobu (NbC) i węgliki chromu $\left(\mathrm{M}_{7} \mathrm{C}_{3}\right)[3,4]$. Spawalność odlewów staliwnych w szczególności o mikrostrukturze austenitycznej jest ograniczona przez segregację dendrytyczną i rozszerzalność cieplną. Ich współczynnik rozszerzalności liniowej jest 1,5x większy od współczynnika dla staliw niestopowych. Autorzy w pracy [5] zaprezentowali technikę spawania z temperaturą podgrzewania wstępnego rzędu $600^{\circ} \mathrm{C}$. Tak wysokie podgrzewanie zwiększa ciągliwość i zmniejsza naprężenia. Dane producentów wskazują, że możliwe jest zwiększenie plastyczności materiału po zastosowaniu starzenia w $1100^{\circ} \mathrm{C}$ przez 1000 godzin $[6,7]$. Pękanie podczas spawania staliw wysokostopowych żaroodpornych GX jest spowodowane występowaniem węglika chromu $\mathrm{M}_{23} \mathrm{C}_{6}$ oraz kruchego związku międzymetaliczny Ni-Nb-Si. Autorzy [8] tłumaczą to przemianą związku międzymetalicznego Ni-Nb-Si w węglik niobu (NbC). Po przemianie pozostaje wysoka zawartość krzemu, która znacząco obniża miejscowo temperaturę topnienia, co prowadzi w czasie chłodzenia do obniżenia plastyczności. Podczas cykli cieplnych w miejscach segregacji dendrytycznych np. na granicach krystalitów, następuje równowagowe nadtapianie lub rozpuszczanie węglików eutektycznych $\mathrm{NbC}$. Krzepnięcie eutektyki węglikowej związane jest ze skurczem i powstaniem pęknięć po granicach ziaren [9].

Dr inż. Sławomir Parzych - Politechnika Krakowska, dr inż. Marek Gucwa - Politechnika Częstochowska, dr inż. Robert Bęczkowski - DRB.

Autor korespondencyjny/Corresponding author. slawomir.parzych@mech.pk.edu.pl 


\section{Metodyka badań, materiał do badań}

Celem pracy było opracowanie dwóch technologii spawania wg PN-EN ISO 11970 [10]. Kwalifikowanie technologii spawania polegało na wykonaniu złącza próbnego przy użyciu spawania łukowego elektrodą nietopliwą w osłonie gazów obojętnych, tj. metody 141 (TIG) z materiałem dodatkowym w gatunku WZ 3545 Zr (tabl. III) wg EN ISO 14343 [11]. Skład chemiczny oraz podstawowe własności mechaniczne wg atestu materiałowego przedstawiono w tablicy II. Materiałem do badań były odlewane żaroodporne rury staliwne w gatunku GX40NiCrNb35-45 wg PN-EN 10295 [12]. Pierwsza $\varnothing 155,8$ x 11,0 mm o nazwie handlowej MANAURITE XTM oraz druga $\varnothing 102,0 \times 11,0$ mm o nazwie handlowej KHR 45A. Zastosowane warunki spawania: pozycja z dołu do góry - PH; gaz/osłona: I1 - argon 5,0; temperatura międzyściegowa: $\max 150^{\circ} \mathrm{C}$. Zgodnie z tablicą 1 PN-EN ISO 11970 [10] na złączach próbnych należy wykonać badania: 100\% badań nieniszczących powierzchniowych i objętościowych: wizualne (VT), penetracyjne (PT) i radiograficzne (RT) oraz badania niszczące: badanie na rozciąganie poprzeczne. Jeśli jest wymagane, wykonuje się badania: zginania poprzecznego, udarności, twardości, makroskopowe i mikroskopowe.

Rura staliwna w stanie lanym charakteryzuje się mikrostrukturą w pełni austenityczną z wydzieleniami węglików bogatych w chrom i niob $\left(\mathrm{M}_{23} \mathrm{C}_{6}, \mathrm{M}_{7} \mathrm{C}_{3}, \mathrm{MC}\right)$ o maksymalnej temperaturze pracy w powietrzu do $1100{ }^{\circ} \mathrm{C}$ bez dodatkowej obróbki cieplnej. Rury staliwne są wytwarzane metodą odlewania odśrodkowego (ang. Centrifugally Casting). Skład chemiczny poszczególnych staliw przedstawiono w tablicach I, II.

Zgłady metalograficzne trawiono $10 \%$ wodnym roztworem $\mathrm{CrO}_{3}$. Badania mechaniczne wykonano na maszynie wytrzymałościowej MTS810. Badania twardości wykonano

Tablica I. Skład chemiczny i własności mechaniczne w temperaturze otoczenia staliwa MANAURITE XTM 5 (\% masowe)

Table I. Chemical composition and mechanical properties at the room temperature of cast steel MANAURITE XTM 5 (\% mass)

\begin{tabular}{|c|c|c|c|c|c|c|c|c|}
\hline $\mathbf{C}$ & $\mathbf{S i}$ & $\mathbf{M n}$ & $\mathbf{P}$ & $\mathbf{S}$ & $\mathbf{C r}$ & $\mathbf{N i}$ & $\mathbf{N b}$ & $\mathbf{T i}$ \\
\hline 0,43 & 1,90 & 1,18 & 0,018 & 0,005 & 36,01 & 44,43 & 0,95 & 0,30 \\
\hline \multicolumn{2}{|c|}{$\mathbf{R}_{\mathrm{p} 0,2}[\mathrm{MPa}]$} & \multicolumn{3}{c|}{$\mathbf{R}_{\mathrm{m}}[\mathrm{MPa}]$} & \multicolumn{3}{c|}{$\mathbf{A}_{5}[\%]$} \\
\hline \multicolumn{3}{|c|}{$\geq 250$} & \multicolumn{3}{|c|}{$\geq 450$} & \multicolumn{3}{c|}{$\geq 5$} \\
\hline
\end{tabular}

Tablica II. Skład chemiczny i własności mechaniczne w temperaturze otoczenia staliwa KHR 45A (wt \%)

Table II. Chemical composition and mechanical properties at the room temperature of cast steel KHR 45A wt \%

\begin{tabular}{|c|c|c|c|c|c|c|c|c|}
\hline $\mathbf{C}$ & $\mathbf{S i}$ & $\mathbf{M n}$ & $\mathbf{P}$ & $\mathbf{S}$ & $\mathbf{C r}$ & $\mathbf{N i}$ & $\mathbf{N b}$ & $\mathrm{Ti}$ \\
\hline 0,53 & 1,80 & 1,78 & 0,015 & 0,008 & 34,51 & 45,68 & 1,95 & 0,42 \\
\hline \multicolumn{2}{|c|}{$\mathbf{R}_{\mathrm{p} 0,2}[\mathrm{MPa}]$} & \multicolumn{3}{|c|}{$\mathbf{R}_{\mathrm{m}}[\mathrm{MPa}]$} & \multicolumn{3}{|c|}{$\mathbf{A}_{5}[\%]$} \\
\hline \multicolumn{3}{|c|}{$\geq 250$} & \multicolumn{3}{|c|}{$\geq 450$} & \multicolumn{3}{c|}{$\geq 5$} \\
\hline
\end{tabular}

Tablica III. Skład chemiczny i własności mechaniczne materiału dodatkowego do spawania WZ $3545 \mathrm{Nb}$ (\% masowe)

Table III. Chemical composition and mechanical properties of filler material WZ $3545 \mathrm{Nb}$ (wt \%)

\begin{tabular}{|c|c|c|c|c|c|c|c|c|}
\hline $\mathbf{C}$ & $\mathbf{S i}$ & $\mathbf{M n}$ & $\mathbf{P}$ & $\mathbf{S}$ & $\mathbf{C r}$ & $\mathbf{N i}$ & $\mathrm{Ti}$ & $\mathbf{N b}$ \\
\hline 0,42 & 1,05 & 1,53 & 0,009 & 0,002 & 35,29 & 45,50 & 0,10 & 1,24 \\
\hline \multicolumn{2}{|c|}{$\mathbf{R}_{\mathrm{p} 0,2}[\mathrm{MPa}]$} & \multicolumn{3}{|c|}{$\mathbf{R}_{\mathrm{m}}[\mathrm{MPa}]$} & \multicolumn{3}{c|}{$\mathbf{A}_{5}[\%]$} \\
\hline \multicolumn{3}{|c|}{$\geq 400$} & \multicolumn{3}{|c|}{$\geq 650$} & \multicolumn{3}{c}{$\geq 8$} \\
\hline
\end{tabular}

na twardościomierzu HPO 250 przy obciążeniu 98,1 N (10kg) metodą Vickersa. Badania udarności wykonano za pomocą młota Charpy'ego o energii początkowej młota $300 \mathrm{~J}$ na próbkach 7,5 x 10 × $55 \mathrm{~mm}$ z karbem "V".

\section{Wyniki badań i ich dyskusja}

Badania wizualne (VT) i badania penetracyjne (PT) nie ujawniły niezgodności spawalniczych. Badania makroskopowe złącza ujawniły poprawny układ ściegów w spoinie bez widocznych wewnętrznych niezgodności spawalniczych (rys. 1).

W celu kompleksowego określenia własności mechaniczne złącza próbnego, oprócz badań wymaganych przez PN-EN ISO 11970 [10], wykonano dodatkowe badania na zginanie poprzeczne, udarności, twardości, metalograficzne makroskopowe i mikroskopowe. W tablicach IV $\div$ VIII przedstawiono wyniki badań niszczących. Badanie rozciągania poprzecznego zakończyło się pozytywnym wynikiem, zerwanie nastąpiło poza spoiną, a wymagana wytrzymałość na rozciąganie została osiągnięta.

Próbę zginania poprzecznego wykonano na dwóch próbkach: od strony lica i grani. Kąt gięcia przy którym próbki się złamały przedstawiono w tablicy V. Próba zginania poprzecznego prowadzona jest w celu sprawdzenia plastyczności złączy oraz wykrycia ewentualnych niezgodności powstałych podczas spawania np. przyklejenia. Kąty przy jakich próbki uległy złamaniu, wskazują na bardzo małą plastyczność złączy.

Próbę udarności wykonano na próbkach o zredukowanych wymiarach ISO Charpy 7,5 (7,5 x 10 x $55 \mathrm{~mm})$ w temperaturze otoczenia. Próbki pobrano i karby nacięto $\mathrm{w}$ następujących strefach złącza: spoinie i strefie wpływu ciepła.

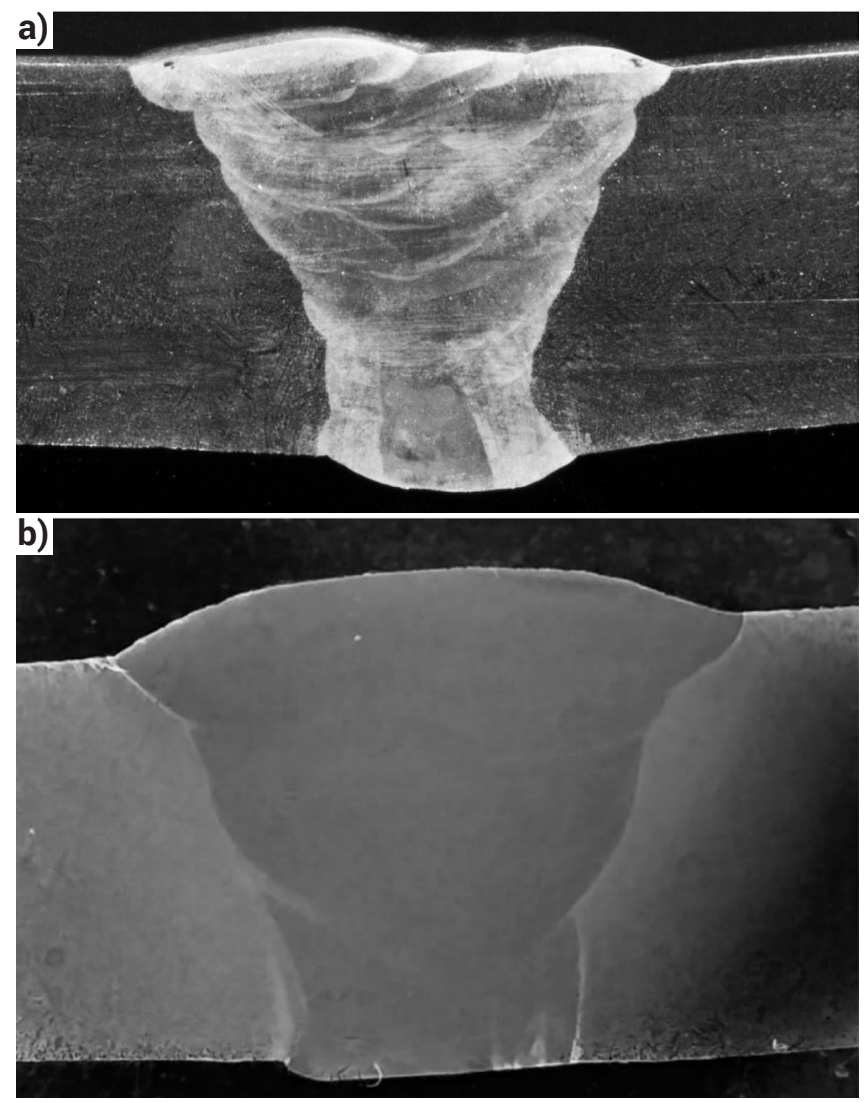

Rys. 1. Makrostruktura złącza spawanego: a) MANAURITE XTM, b) KHR 45A

Fig. 1. Macrostructure of the welded joint: a) MANAURITE XTM, b) KHR 45A 
Tablica IV. Wyniki próby rozciągania poprzecznego złącza spawanego staliwa MANAURITE XTM oraz KHR 45A

Table IV. Transverse tensile test results concerning the test joint made in cast steel MANAURITE XTM and KHR 45A

\begin{tabular}{|c|c|c|c|c|}
\hline \multirow{2}{*}{$\begin{array}{c}\text { Oznaczenie } \\
\text { próbki }\end{array}$} & \multirow{2}{*}{$\begin{array}{c}\text { Wyma- } \\
\text { gania }\end{array}$} & $\begin{array}{c}\mathbf{R}_{\mathbf{m}} \\
{[\mathrm{MPa}]}\end{array}$ & $\begin{array}{c}\text { Miejsce } \\
\text { zerwania }\end{array}$ & Wyniki badań \\
\cline { 3 - 5 } & $\mathbf{4 4 0}$ & - & - \\
\hline \multirow{2}{*}{$\begin{array}{c}\text { MANAURITE } \\
\text { XTM }\end{array}$} & $\mathrm{R} 1$ & 462 & poza spoiną & pozytywny \\
\cline { 3 - 5 } & $\mathrm{R} 2$ & 443 & poza spoiną & pozytywny \\
\hline \multirow{2}{*}{ KHR 45A } & $\mathrm{R} 1$ & 443 & poza spoiną & pozytywny \\
\cline { 2 - 5 } & $\mathrm{R} 2$ & 447 & poza spoiną & pozytywny \\
\hline
\end{tabular}

Praca łamania niezależnie od miejsca próby była na bardzo niskim poziomie (tabl. VI). Nie można odnieść otrzymanych wartości pracy łamania do wartości pracy łamania materiatu rodzimego $z$ powodu braku takich informacji w normie materiałowej PN-EN 10295. Dodatkowo materiał lany, jakim jest odlew staliwny, charakteryzuje się niskimi własnościami mechanicznymi w porównaniu do materiałów przerobionych plastycznych.

Wyniki pomiarów twardości na przekroju złącza spawanego GX40NiCrSiNb35-25 nie odbiegają od typowych dla tego typu materiałów. Nie ma gwałtownych zmian twardości w zależności od badanych stref złącza (tabl. VII, VIII). Podobnie jak w przypadku próby udarności, nie ma informacji na jakim poziomie jest twardość materiału rodzimego.

Można zauważyć, że w przypadku zastosowania materiału KHR 45A średnia twardość na przekroju złącza jest niższa w porównaniu do MANAURITE XTM o ok. 40 $\div 50$ jednostek twardości. Jest to prawdopodobne spowodowane większą objętością fazy węglikowej. Aby to potwierdzić, należy wykonać badania mikroskopowe.
Tablica V. Wyniki próby zginania poprzecznego złączy spawanych MANAURITE XTM oraz KHR 45A

Table V. Test results concerning the bending of the test joint made in cast steel MANAURITE XTM and KHR 45A

\begin{tabular}{|c|c|c|c|c|c|}
\hline \multicolumn{2}{|c|}{ Oznaczenie próbki } & $\begin{array}{l}\text { Średnica } \\
\text { trzpienia }\end{array}$ & $\begin{array}{c}\text { Kąt } \\
\text { zgina- }\end{array}$ & $\begin{array}{c}\text { Stro- } \\
\text { na }\end{array}$ & Uwagi \\
\hline \multirow{4}{*}{$\begin{array}{c}\text { MANAURITE } \\
\text { XTM }\end{array}$} & TFBB1 & $90 \mathrm{~mm}$ & $9^{\circ}$ & lico & $\begin{array}{c}\text { Pełne } \\
\text { złamanie }\end{array}$ \\
\hline & TFBB2 & $90 \mathrm{~mm}$ & $11^{\circ}$ & lico & $\begin{array}{c}\text { Pełne } \\
\text { złamanie }\end{array}$ \\
\hline & TRBB1 & $90 \mathrm{~mm}$ & $14^{\circ}$ & grań & $\begin{array}{c}\text { Pełne } \\
\text { złamanie }\end{array}$ \\
\hline & TRBB2 & $90 \mathrm{~mm}$ & $16^{\circ}$ & grań & $\begin{array}{c}\text { Pełne } \\
\text { złamanie }\end{array}$ \\
\hline \multirow{4}{*}{ KHR 45A } & TFBB1 & $90 \mathrm{~mm}$ & $11^{\circ}$ & lico & $\begin{array}{c}\text { Pełne } \\
\text { złamanie }\end{array}$ \\
\hline & TFBB2 & $90 \mathrm{~mm}$ & $12^{\circ}$ & lico & $\begin{array}{c}\text { Pełne } \\
\text { złamanie }\end{array}$ \\
\hline & TRBB1 & $90 \mathrm{~mm}$ & $10^{\circ}$ & grań & $\begin{array}{c}\text { Pełne } \\
\text { ztamanie }\end{array}$ \\
\hline & TRBB2 & $90 \mathrm{~mm}$ & $13^{\circ}$ & grań & $\begin{array}{c}\text { Pełne } \\
\text { złamanie }\end{array}$ \\
\hline
\end{tabular}

Tablica VI. Wyniki pracy łamania złączy spawanych

Table VI. Results concerning the impact strength of the joint made in cast steel

\begin{tabular}{|c|c|c|c|c|c|c|c|c|}
\hline \multirow{2}{*}{\multicolumn{2}{|c|}{ Oznaczenie próbki }} & \multirow{3}{*}{$\begin{array}{c}\text { Zestaw } \\
1 \div 3\end{array}$} & \multirow{3}{*}{ 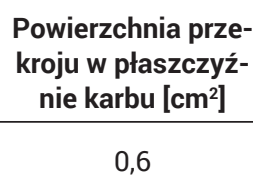 } & \multirow{3}{*}{$\begin{array}{c}\begin{array}{c}\text { Temperatura } \\
\text { badania }\end{array} \\
+21^{\circ} \mathrm{C}\end{array}$} & \multicolumn{3}{|c|}{ Praca łamania KV [J] } & \multirow{3}{*}{$\begin{array}{c}\begin{array}{c}\text { Wartość } \\
\text { średnia [J] }\end{array} \\
4\end{array}$} \\
\hline & & & & & & & & \\
\hline \multirow{2}{*}{ MANAURITE XTM } & VWT (spoina) & & & & 5 & 3 & 3 & \\
\hline & VHT (SWC) & $4 \div 6$ & 0,6 & $+21^{\circ} \mathrm{C}$ & 3 & 3 & 3 & 3 \\
\hline \multirow{2}{*}{ KHR 45A } & VWT (spoina) & $1 \div 3$ & 0,6 & $+21^{\circ} \mathrm{C}$ & 6 & 4 & 6 & 5 \\
\hline & VHT (SWC) & $4 \div 6$ & 0,6 & $+21^{\circ} \mathrm{C}$ & 5 & 8 & 6 & 6 \\
\hline
\end{tabular}

Tablica VII. Wyniki pomiarów twardości na przekroju złącza spawanego MANAURITE XTM

Table VII. Results of hardness measurements concerning the cross-sectional hardness of the welded joints made in cast steel MANAURITE XTM

\begin{tabular}{|c|c|c|c|c|c|c|c|c|c|c|c|c|c|c|c|}
\hline Linia pomiarowa & 1 & 2 & 3 & 4 & 5 & 6 & 7 & 8 & 9 & 10 & 11 & 12 & 13 & 14 & 15 \\
\hline lico & 217 & 214 & 216 & 215 & 213 & 208 & 204 & 208 & 216 & 217 & 210 & 216 & 211 & 218 & 214 \\
\hline grań & 225 & 213 & 224 & 210 & 217 & 222 & 214 & 206 & 192 & 198 & 205 & 207 & 206 & 213 & 213 \\
\hline
\end{tabular}

Tablica VIII. Wyniki pomiarów twardości na przekroju złącza spawanego KHR 45A

Table VIII. Results of hardness measurements concerning the cross-sectional hardness of the welded joints made in cast steel KHR 45A

\begin{tabular}{|c|c|c|c|c|c|c|c|c|c|c|c|c|c|c|c|}
\hline Linia pomiarowa & $\mathbf{1}$ & $\mathbf{2}$ & $\mathbf{3}$ & $\mathbf{4}$ & $\mathbf{5}$ & $\mathbf{6}$ & $\mathbf{7}$ & $\mathbf{8}$ & $\mathbf{9}$ & $\mathbf{1 0}$ & $\mathbf{1 1}$ & $\mathbf{1 2}$ & $\mathbf{1 3}$ & $\mathbf{1 4}$ & $\mathbf{1 5}$ \\
\hline lico & 166 & 191 & 163 & 191 & 197 & 205 & 193 & 191 & 176 & 193 & 192 & 189 & 159 & 157 & 158 \\
\hline grań & 180 & 177 & 168 & 198 & 205 & 206 & 222 & 221 & 227 & 207 & 206 & 202 & 170 & 169 & 168 \\
\hline
\end{tabular}




\section{Podsumowanie}

Przeprowadzone badania dały wynik pozytywny i pozwoliły na wystawienie protokołu kwalifikowania technologii spawania WPQR zgodnie z PN-EN ISO 11970. Należy jednak zaznaczyć, że badane złącza mają bardzo niską plastyczność i udarność, co związane jest prawdopodobnie z wydzielaniem się węglików i związków międzymetalicznych po granicach ziaren austenitu. Zauważalna jest również różnica w twardości badanych złączy. Złącza wykonane z użyciem materiału KHR 45A charakteryzowały się zdecydowanie mniejszą twardością materiału rodzimego niż złącza wykonane z materiału MANAURITE XM. Również wyniki badań udarności wskazują na pewne różnice we właściwościach materiału, wynikające prawdopodobnie z różnic w składach chemicznych porównywanych materiałów, jak i niskich właściwości plastycznych charakteryzujących materiały odlewane. Można jednak przyjąć, że niezależnie od producenta wyniki badań niszczących są na podobnym poziomie.

\section{Literatura}

[1] ASM Handbook, Volume 1, Properties and Selection: Irons, Steels, and HighPerformance Alloys, ASM International, Materials Park, Ohio, 2005.

[2] Babakr A.M., Al.-Ahamari A., Al.-Jumayiah K., Habiby F.: Sigma chase formation and embrittlement of cast iron-chromium Nikel (Fe-Cr-Ni) alloys, Journal of Minerals \& Materials Characterization \& Engineering, 2008, vol. 7, No. 2, pp. 127-145.

[3] Patchett, B.M. and Skwarok, R.W.: Welding metallurgy of 20Cr-32Ni-Nb and HP45 castings, Materials for Resource recovery and Transport, Metallurgical Society of CIM, 1998.

[4] Shinozaki, K. et al: Deterioration of weldability of long term aged HP heat-resistant cast steel containing $\mathrm{Nb}, \mathrm{Mo}$ and $\mathrm{W}$, Quarterly Journal of the Japan Welding Society, Vol. 12, No. 2, 1998, pp. 223-232.

[5] Vekeman J., De Waele M.: Repair welding of HP40-Nb, Welding in the World, 2010, Vol. 54, No 3/4, pp. 34-42.
[6] http://www.kubotamaterials.com/alloys/heat_resistant/KHR45A.pdf (7.04.2018).

[7] http://www.manoir-industries.com/site/docs_wsw/RUB_75/FICHE_INTERNET_XTM.pdf (7.04.2018).

[8] Shi S., Lippold J. C., Ramire J.: Hot Ductility Behavior and Repair Weldability of Service-Aged, Heat-Resistant Stainless Steel Castings, Welding Research, 2010, Vol. 89

[9] Tasak E.: Metalurgia spawania, JAK, 2008.

[10] PN-EN ISO 11970:2009 Instrukcja technologiczna spawania i kwalifikowanie technologii spawania produkcyjnego odlewów staliwnych.

[11] PN-EN ISO 14343:2010 Materiały dodatkowe do spawania - Druty elektrodowe, taśmy elektrodowe, druty i pręty do spawania łukowego stali nierdzewnych i żaroodpornych - Klasyfikacja.

[12] PN-EN 10295:2004 Odlewy ze staliwa żaroodpornego. 